\title{
Síndrome de Kartagener
}

\section{Kartagener syndrome}

\author{
Marysabel Cogollo-González, Emily Rincón-Álvarez • Bogotá, D.C. (Colombia)
}

DOI: https://doi.org/10.36104/amc.2022.2280

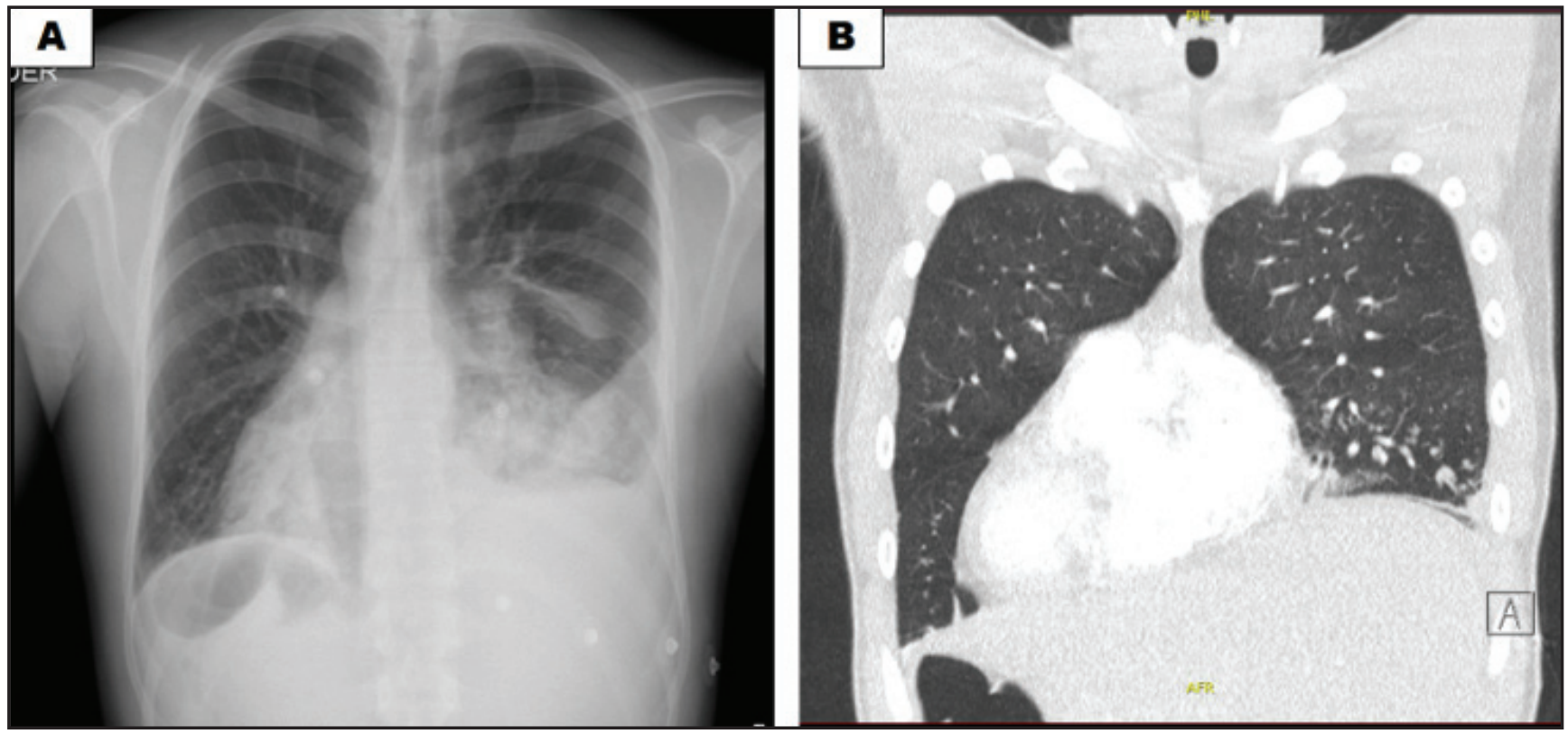

Figura 1. A: radiografía de tórax, en proyección postero-anterior, se identifica una opacidad alveolar en lóbulo inferior izquierdo, derrame pleural ipsilateral y signos de pérdida de volumen con retracción del hemidiafragma, dextrocardia y cámara gástrica derecha. B: tomografía de tórax, plano coronal, muestra situs inversus completo: corazón y estómago hacia el lado derecho e hígado hacia el lado izquierdo.

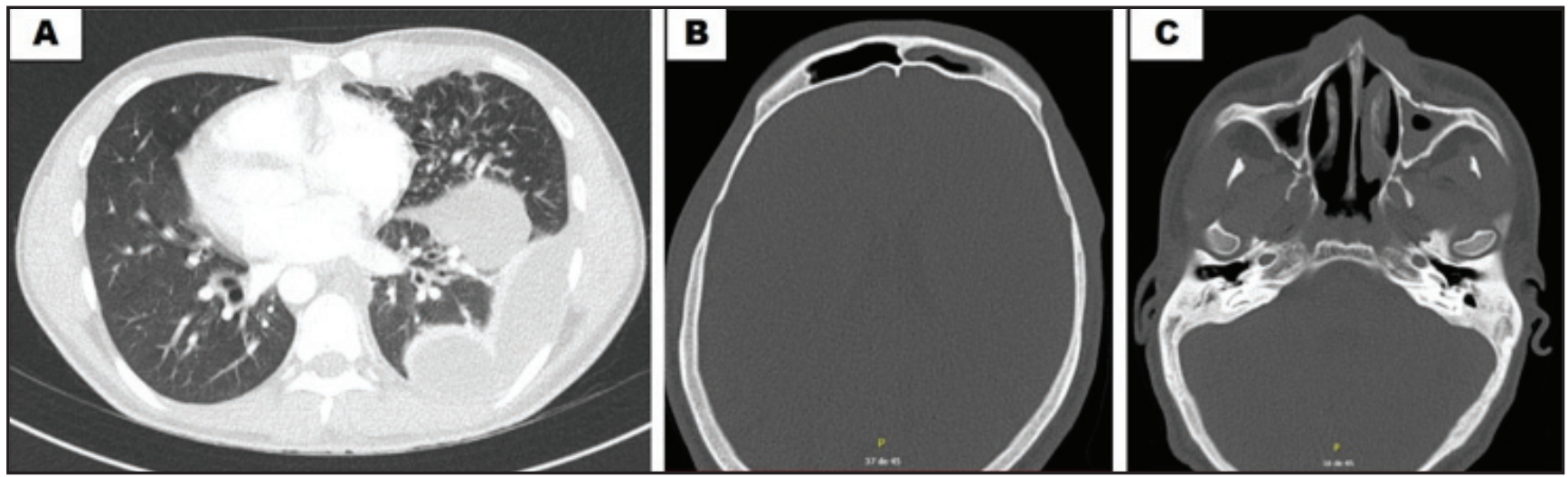

Figura 2. A: tomografía de tórax, plano axial, con derrame pleural izquierdo, engrosamiento peribronquial y bronquiectasias bilaterales, algunas con tapón mucoso. B: tomografía de senos paranasales, muestra sinusitis frontal. C: etmoidal y maxilar bilateral.

Masculino de 23 años, con antecedentes de sinusitis recurrente. Ingresa por dolor pleurítico y fiebre. Los exámenes mostraron un empiema izquierdo, situs inversus, bronquiectasias y sinusitis (Figuras 1 y 2). Se realizó un diagnóstico de síndrome de Kartagener, requirió manejo antibiótico y quirúrgico para el empiema, con
Dra. Marysabel Cogollo-González: Internista. Residente de Neumología Universidad de la Sabana; Dra. Emily Rincón-Álvarez: Internista, Neumóloga. Fundación Cardio Infantil, Instituto de Cardiología. Bogotá, D.C. (Colombia).

Correspondencia: Dra. Marysabel Cogollo-González. Bogotá, D.C. (Colombia).

E-Mail: marysabelcogo@unisabana.edu.co

Recibido: 29/VIII/2021 Aceptado: 20/X/2021 
mejoría clínica. Una biopsia ciliar de mucosa nasal, fue compatible con discinesia ciliar.

El síndrome de Kartagener es un trastorno hereditario autosómico recesivo, subconjunto de la discinesia ciliar primaria, caracterizado por la tríada: sinusitis crónica, bronquiectasia y situs inversus (1). Los criterios diagnósticos recomendados incluyen antecedentes de infección bronquial crónica y rinitis desde la infancia, con uno o más de lo siguiente: (a) situs inversus o dextrocardia en el paciente/hermano, (b) espermatozoides vivos pero inmóviles, (c) aclaramiento traqueobronquial ausente o alterado, y (d) cilios que muestran un defecto ultraestructural característico en el microscopio electrónico (2). El manejo es multidisciplinario, se recomienda la fisioterapia, los antibióticos, las vacunas y el trasplante pulmonar en la enfermedad avanzada $(1,3)$.

\section{Referencias}

1. Tadesse A, Alemu H, Silamsaw M, Gebrewold Y. Kartagener's syndrome: a case report. Journal of Medical Case Reports. 2018;12(1):5.

2. Fraser RS, Muller NL, Colman N, Pare PD. Bronchiectasis and other bronchial abnormalities. In: Fraser RS, Muller NL, Colman N, Pare PD, editors. Diagnosis of diseases of the chest. 4th ed. Philadelphia: W.B. Saunders Company; 1999. p. 2281-3.

3. Yamamoto H, Sugimoto S, Miyoshi K, Otani S, Yamane M, Toyooka S. Lung transplantation for Kartagener syndrome: technical aspects and morphological adaptation of the transplanted lungs. General Thoracic and Cardiovascular Surgery. 2021;69(3):588-92. 